\title{
Space-time patterns of genetic structure within a stand of Androcymbium gramineum (Cav.) McBride (Colchicaceae)
}

\author{
JULI CAUJAPÉ-CASTELLS* \& JOAN PEDROLA-MONFORT \\ Estació Internacional de Biologia Mediterrània - Jardí Botànic Marimurtra, Psg. Karl Faust, 10, Ap. de Correus 112, \\ 17300 Blanes (Girona), Spain
}

\begin{abstract}
Space-time patterns of genetic structure in the largest known Spanish stand of Androcymbium gramineum were explored through spatial autocorrelation on allele frequencies at 17 allozymic loci. Our results strongly suggest that the consistent overall profiles of short-distance genetic structure detected have evolved in a scenario of prolonged habitat uniformity by the action of prolific vegetative reproduction overlaid with a minor incidence of outcrossing and self-fertilization. Investigation of the temporal component of spatial genetic structure through the assessment of differently aged cohorts of plants provided evidence that patch sizes in this stand are progressively enlarged in the absence of microhabitat differentiation. These results explain the maintenance of large amounts of variability in this endangered endemic species.
\end{abstract}

Keywords: allozymes, Androcymbium, genetic structure, population growth, spatial autocorrelation, vegetative reproduction.

\section{Introduction}

Plant populations can manifest different patterns of genetic structure owing to a variety of demographic and life history traits (Levin \& Kerster, 1974; Antonovics \& Levin, 1980; Schnabel et al., 1991). From a general point of view, the genetic structure of natural populations can be conceived as the organization of variability emerging from the continued interaction between ecological conditions and historical contingency. Therefore, it is primarily a phenomenon restricted to a given space and, as such, bound to reflect differences in the size of populations and in the distribution of individuals within them. As first recognized by Wright (1938, 1946), small size has great significance in the population breeding structure, because it leads to impoverished variability through progressively higher levels of inbreeding and genetic drift. Within an evolutionary context, it is generally agreed that a random distribution of intrapopulational genetic variability contributes to progressive loss of variation, which reduces the ability of populations to

*Present address and correspondence: Department of Botany, The University of Texas at Austin, Austin, TX 78713-7640, U.S.A. E-mail: boam124@utxvms.cc.utexas.edu adapt to changing environments and increases their susceptibility to external pressures (Barrett \& Kohn, 1991).

Large natural populations, in which drift is not a factor, are generally assumed to be subdivided into demes of related individuals (Bradshaw, 1972; Levin \& Kerster, 1974; Schaal, 1975). Consistently, most studies involving large populations have elicited patterns of spatial genetic organization over short distances (Epperson \& Clegg, 1986; Schoen \& Latta, 1989; Perry \& Knowles, 1991; Schnabel et al., 1991; Wagner et al., 1991; Shapcott, 1995), although some exceptions seem to occur (Levin, 1976; Dewey \& Heywood, 1988). The existence of spatial structuring in large populations facilitates the generation and maintenance of high levels of variability with which to sustain efficient reproductive performance, survive stochastic events or adjust to novel fluctuating environments (Huenneke, 1991).

Given that the demographic dynamics of populations usually impact directly on the amount and distribution of their levels of variation, patterns of genetic structure can also be affected by time. Even in the absence of environmental alterations, the change in density concomitant to population growth appears to be able to influence the spatial organiza- 
tion of genetic variability. In both insect- and windpollinated species, increased density usually relates to lower pollen dispersal because of compensation adjustments of pollinators and to the increased probability of pollen impaction (Antonovics \& Levin, 1980). Therefore, it seems likely that as a population becomes denser, near neighbours are more closely related, giving rise to the abovementioned profile of semi-isolated patches. Nevertheless, owing to the impossibility of reliably ageing most plant species and because sampling must take place over a short period, empirical evidence indicating the effect of time upon genetic structure is scarce. This present shortage of data has important implications for theoretical developments because, in contrast to these, no remarkable variation resulting from the time component in the genetic structure of natural populations has been reported, even although long-term scales have been considered (Levin, 1976; Linhart et al., 1979).

In this context, fine-scale studies of plant populations are clearly needed not only to throw light on the influence of population growth on patterns of genetic structure, but also to facilitate insight into the mechanisms by which variability originates and is maintained.

Androcymbium gramineum (Cav.) McBride is an endangered endemic cormous monocotyledon that has sets of disjunct populations on both sides of the Straits of Gibraltar (Fig. 1). In the Spanish province of Almería, there are 10 known stands, which show a remarkable variation in size. They always occur in sheltered locations, most of which have remained

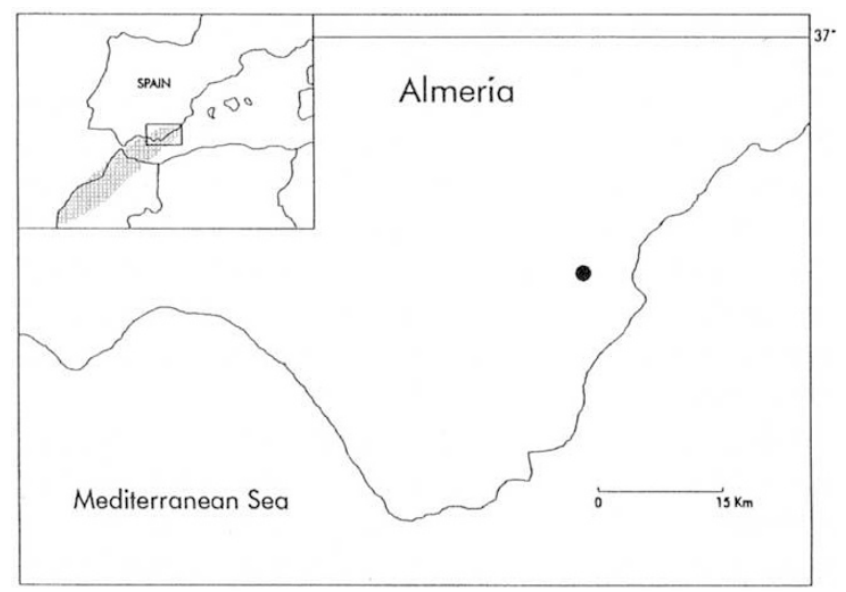

Fig. 1 Geographical distribution of Androcymbium gramineum (shaded area) and location of the stand 'Charco del Lobo' in Almería. undisturbed owing to their remote location. Individuals can live for a maximum of 40 years, as estimated from the number of tunics they accumulate around the corm.

Despite the fact that its range is restricted and that its pollen and seeds have no special adaptations to aid dispersal, most of the high levels of genetic variation detected in $A$. gramineum reside within populations (Pedrola-Monfort \& Caujapé-Castells, 1994). Clearly, a large part of the explanation for this confluency lies in its reproductive features, which allow this species to maintain rich stocks of variability. Plants are hermaphrodites that can develop 1-15 flowers in direct relation to corm size. Antheses overlap within 2 months. They are preferential entomogamous outcrossers that can also achieve selfing, either by autogamy or by geitonogamy. Their known pollinators are the bug Spilosthetus sp. and the bee Apis mellifera. According to the classification of pollen-ovule $(\mathrm{P} / \mathrm{O})$ ratios in Cruden (1976) and to its floral traits, A. gramineum should be considered xenogamous (J. Pedrola-Monfort \& J. Caujapé-Castells, in preparation). Seed dispersal is gravity mediated, with its indehiscent capsules spreading $0.5-1 \mathrm{~m}$ from the mother plant. However, windstorms and seasonal floods can occasionally carry capsules further. Seeds are released from the capsule after about a year and show dormancy, which, as a mechanism of varying dispersal over time, can buffer external pressures. Germination can take up to 5 years, and this is a major hindrance for estimating the basic parameters of reproductive biology. Data compiled in the greenhouse indicate that vegetative growth can be considerable and might account for much population regeneration in nature. Androcymbium gramineum displays high values of inbreeding (Caujapé-Castells, 1995), as estimated from $F_{\mathrm{ST}}$ (Wright, 1978).

These attributes constitute indirect evidence that $A$. gramineum populations might exhibit spatial genetic structuring. The first objective of this study is to describe the distribution of genetic variability in the demographically largest Spanish stand of this endangered endemic. In an attempt to explain the maintenance of high levels of variability in A. gramineum, our second goal is to examine the temporal component of its genetic structure. Of instrumental importance in fulfilling this last objective, corm growth in the genus Androcymbium proceeds through the yearly production of a new coriaceous tunic that remains firmly stuck on top of those accumulated during the life of the plant, thereby allowing reliable ageing of individuals. 


\section{Methods}

\section{Sampling}

The sampled population, named 'Charco del Lobo' $(\mathrm{CH})$, is by far the largest known stand of $A$. gramineum, with an estimated size of 50000 individuals. They form a dense continuous prairie of about a hectare in a small valley, which is flooded during the rainy season. It is situated near the village of Campohermoso (province of Almería) (Fig. 1). Because plants in this population are not structured into physical clumps, clones are not easily identifiable. Intensive sampling was conducted within a transect of $70 \mathrm{~m}$, resulting in a total of 200 individuals. In all cases, they were assigned a code and a pair of map co-ordinates before sampling. Subsequently, they were unearthed, put into paper bags and carried to the Marimurtra Botanical Garden in Blanes (Girona). Because the number of tunics formed by the corm provides a direct estimate of the age of the plants, it was recorded for each of the sampled specimens. They were then planted in a greenhouse using a homogeneous substrate. Two of them died.

\section{Electrophoretic analyses}

Horizontal starch-gel electrophoresis was carried out with fresh leaf tissue, as described elsewhere (Pedrola-Monfort \& Caujapé-Castells, 1994), and resulted in the resolution of 17 putative loci inferred from 11 enzyme systems: aconitase (Aco2, Aco3, EC 4.2.1.3); alcohol dehydrogenase (Adh, EC 1.1.1.1); formate dehydrogenase ( $F d h, \mathrm{EC} 1.2 .1 .2)$; glutamate dehydrogenase (Gdh, EC 1.4.1.3); glutamatic-oxaloacetic transaminase (Got1, EC 2.6.1.1); malate dehydrogenase (Mdh1, Mdh2, EC 1.1.1.37); malic enzyme ( $M e$, EC 1.1.1.40); phosphoglucoisomerase (Pgi, EC 5.3.1.9); phosphoglucomutase (Pgm1, Pgm2, EC 5.4.2.2); 6-phosphogluconate dehydrogenase (6Pgd1, 6Pgd2, 6Pgd3, 6Pgd4, EC 1.1.1.44) and shikimate dehydrogenase (Sdh1, EC 1.1.1.25). Allozymes had banding patterns consistent with expected quate rnary structures.

\section{Data processing}

Basic descriptors of populational genetic variability were obtained across all these loci by implementing the matrix of absolute genotype frequencies in BIOSYS-1 version 1.7 (Swofford \& Selander, 1989). Patterns of genetic structure were assessed using spatial autocorrelation analyses (Sokal \& Oden, 1978). To carry them out, only alleles with frequency values above 0.040 were processed and, at diallelic loci, only one allele was considered (as the other one would offer identical information). These genetic data were recoded so that each plant was assigned a frequency value of $0.0,0.5$ or 1.0 depending on the absence, presence in heterozygosity or presence in homozygosity of every submitted allele at every locus, respectively. The resulting matrices were loaded in SAAP version 4.3 (Wartenberg, 1989), which calculated Moran's coefficient of spatial autocorrelation (Cliff \& Ord, 1973). Moran's $I$ varies from -1 to +1 , and its expected value is given by the expression $\mathrm{E}(I)=-1 /(n-1)$, where $n$ is the total number of individuals in the sample (Sokal \& Oden, 1978). Departures from the expected value of $I$ for each distance class and overall correlogram significances were also tested for every allele by SAAP. To analyse the temporal component of genetic structure in this population, the sample was divided into four subsets, corresponding to individuals with more than 15, 11, 8 and 6 tunics and coded $t=1$, $t=2, t=3$ and $t=4$, respectively. All analyses were performed with five distance classes to allow comparison among the patterns emerging from the whole sample and those from each of the temporal subsets (which, logically, have much smaller sizes). All correlograms, which plot the change of Moran's $I$ with distance, were produced by SYSTAT version 5 (1992).

\section{Results}

The histogram of age classes (Fig. 2) demonstrates that population $\mathrm{CH}$ is of mixed age, with most individuals falling in the interval from 4 to 12 tunics. As expected, the mean number of alleles per locus (3.12) is considerably higher than that found in the rest of the populations of $A$. gramineum (PedrolaMonfort \& Caujapé-Castells, 1994). The estimated

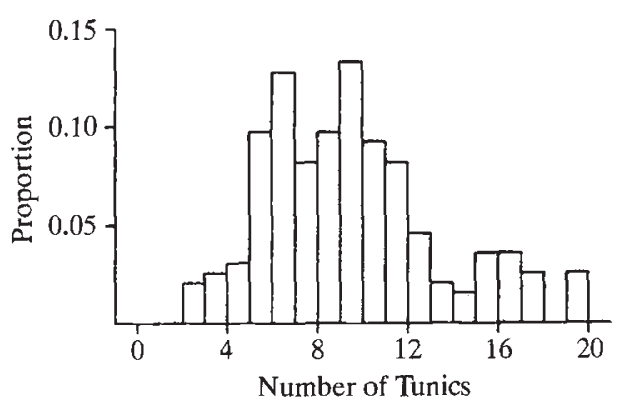

Fig. 2 Age dendrogram ( 1 tunic $=1$ year $)$ corresponding to the 200 sampled individuals of Androcymbium gramineum. 
values of the mean fixation index (Wright, 1978) and mean expected heterozygosity are also high for this stand ( $F=0.249$ and $H_{\mathrm{e}}=0.349$, respectively).

Most of the alleles displayed significant spatial autocorrelation. As shown in Table 1, 26 alleles (87 per cent of the total number submitted) rendered correlograms significant at $P<0.01$, all of which showed significant positive autocorrelation in the first distance class (mean $I=0.29$ ). Twenty-one were significant in the fifth distance class, not always negatively, but with a mean $I$-value of -0.15 . Undoubtedly, the large size of our sample had a great influence on these results, in which values as low as 0.03 are significant. There were no remarkable differences among the correlograms corresponding to different loci. The average multilocus correlogram (Fig. 3a) displays a regular monotonic decline in the values of Moran's $I$ through the five distance classes, with a slump of 0.31 I units between the first and the second, and with the maximum absolute difference between two values ( $0.44 I$ units) occurring between the first and the fifth distance classes. The only $x$-axis intercept in this correlogram occurs at about $15 \mathrm{~m}$. According to Sokal (1979), the first $x$-axis intercept is an operational estimate of the average length of the shortest side of true patches that are irregular in shape or variable in size. Average multilocus correlograms calculated independently in each of four age classes (Fig. 3b-e) show a close similarity with that of the whole data set.

To study the effects of population growth on the spatial structuring of genetic variability, the sample of $\mathrm{CH}$ was divided into four sets, which represent
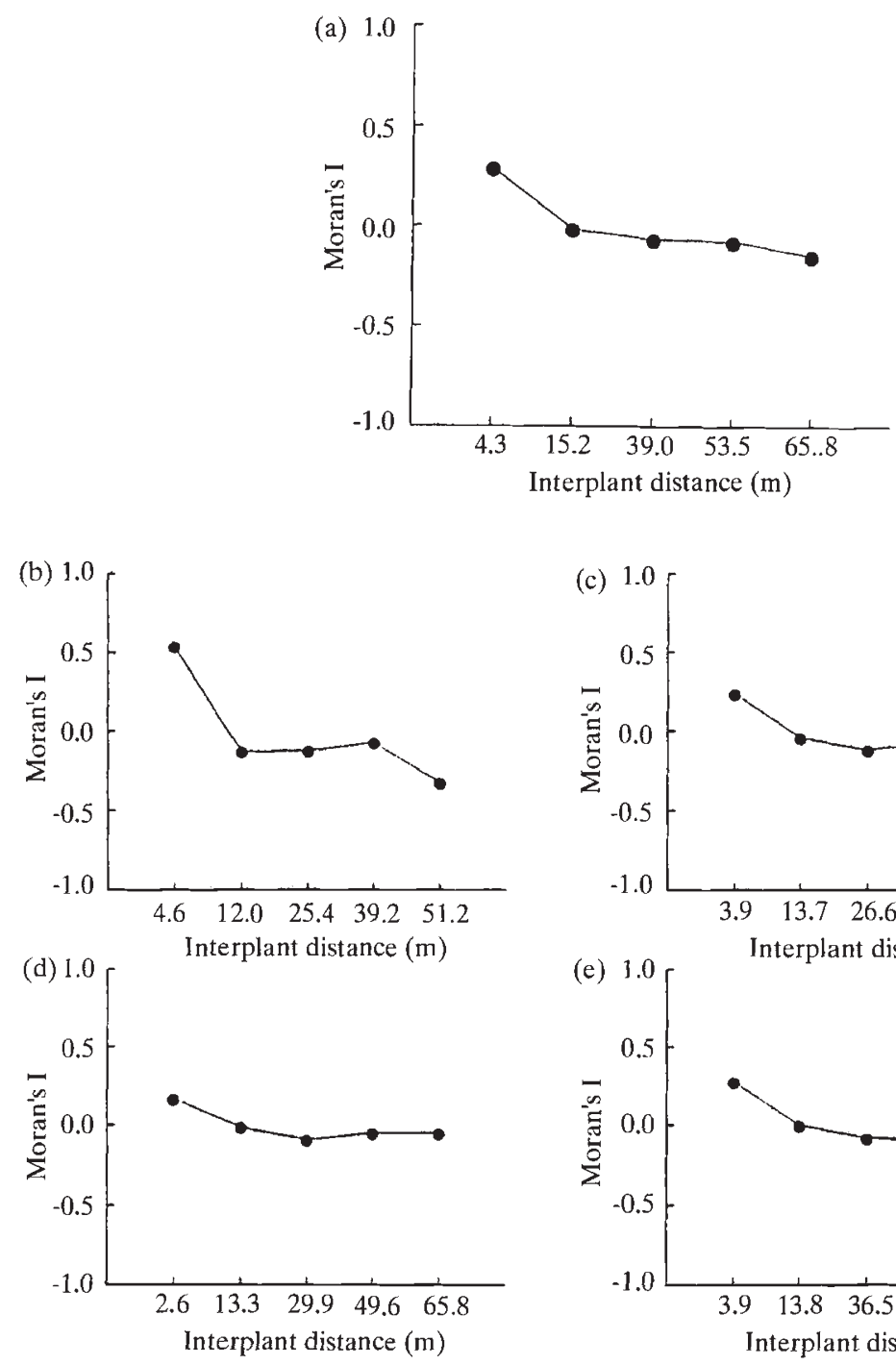
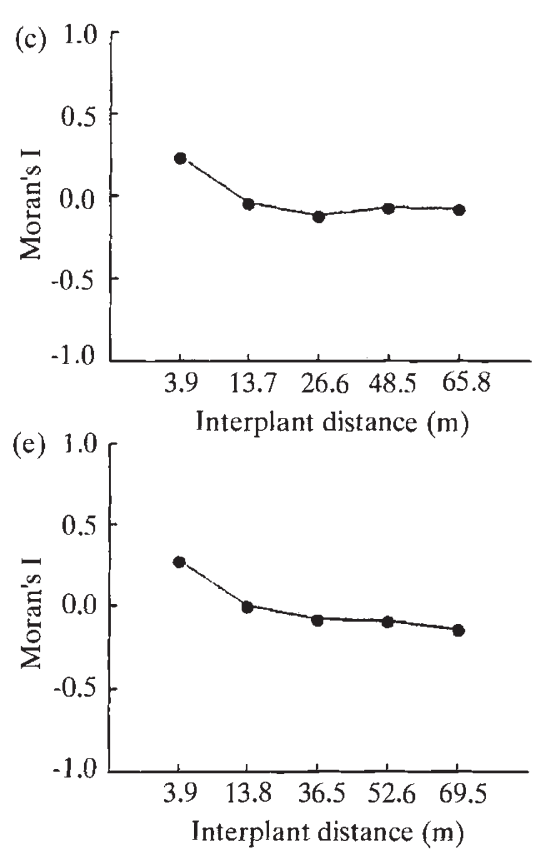

Fig. 3 Average multilocus correlograms for the whole sample of Androcymbium gramineum (a), and for each of four age intervals into which it was subdivided: (b) $1-5$ tunics $(n=34$ individuals); (c) $6-8$ tunics $(n=61$ individuals); (d) 9-11 tunics ( $n=60$ individuals); (e) 12-19 tunics ( $n=43$ individuals). Linear interpolation estimates of the $x$-axis intercepts for these representations are $15.2 \mathrm{~m}, 10.5$ $\mathrm{m}, 13.45 \mathrm{~m}, 11.23 \mathrm{~m}$ and $12.4 \mathrm{~m}$, respectively. 
consecutive stages of individual recruitment. By and large, the average multilocus correlograms of these sets are similar, both among themselves and relative to the overall mean correlogram for $\mathrm{CH}$ in Fig. 3a: the sharpest single-step slump of Moran's $I$ always occurs between the first and second distance class, and the maximum difference between two values of Moran's $I$ is that between the first and the fifth distance class. However, population growth seems to influence patterns of spatial genetic structure in two aspects: through the progressive decay in the difference between the values of Moran's $I$ in the first and the second distance class, and by enlarging the size of homogeneous areas, as is evident from the repre- sentation of the $x$-intercept as a function of time (Fig. 4).

The genotypic site map of locus 6 Pgd 4 at each of these four stages (Fig. 5) shows that this large population of $A$. gramineum recruits mainly by the multiplication of old genotypes and by the appearance of some new combinations between alleles previously detected in our transect. At $t=2$, the sample incorporates two alleles (6Pgd4-b and 6Pgd4-g) and exhibits four additional genotypic combinations: $b b$, $d g, e g$ and $g g$, with approximate co-ordinates $(1,2.5)$ $(45,5)(50,5)$ and $(51,5)$, respectively. At $t=3$, one previously undetected allele $(6 P g d 4-f)$ arises along with three new genotypes: $a b$ at $(1,4), d f$ at $(2,2.5)$

Table 1 Values of Moran's coefficient of spatial autocorrelation in the surveyed stand of Androcymbium gramineum for the alleles whose correlograms were significant at $P<0.01$

\begin{tabular}{|c|c|c|c|c|c|c|c|}
\hline \multirow{2}{*}{\multicolumn{2}{|c|}{ Locus/allele }} & \multicolumn{5}{|c|}{ Distance class } & \multirow{2}{*}{$\begin{array}{c}\text { Mean } \\
\text { frequency }\end{array}$} \\
\hline & & $\frac{1}{0.81^{* *}}$ & $\frac{2}{0.03^{* *}}$ & $\frac{3}{-0.10^{* *}}$ & $\frac{4}{-0.28^{* *}}$ & $\frac{5}{-0.49^{* *}}$ & \\
\hline Aco2 & $\begin{array}{l}b \\
c \\
d\end{array}$ & $\begin{array}{l}0.81^{* *} \\
0.86^{* *} \\
0.12^{* *}\end{array}$ & $\begin{array}{l}0.03^{* *} \\
-0.02 \\
-0.15^{* *}\end{array}$ & $\begin{array}{c}-0.10^{* *} \\
-0.13^{* *} \\
0.08^{*}\end{array}$ & $\begin{array}{l}-0.28^{* *} \\
-0.24^{* *} \\
-0.11^{* *}\end{array}$ & $\begin{array}{c}-0.49^{* *} \\
-0.50^{* *} \\
0.03^{*}\end{array}$ & $\begin{array}{l}0.064 \\
0.865 \\
0.060\end{array}$ \\
\hline Pgm1 & $\begin{array}{l}b \\
c \\
d\end{array}$ & $\begin{array}{l}0.39^{* *} \\
0.11^{* *} \\
0.37^{* *}\end{array}$ & $\begin{array}{l}0.05^{* *} \\
-0.02 \\
-0.08^{* *}\end{array}$ & $\begin{array}{r}0.08^{* *} \\
0.10^{* *} \\
-0.16^{* *}\end{array}$ & $\begin{array}{r}-0.03^{* *} \\
-0.09^{* *} \\
0.20^{* *}\end{array}$ & $\begin{array}{l}-0.52^{* *} \\
-0.13^{* *} \\
-0.36^{* *}\end{array}$ & $\begin{array}{l}0.101 \\
0.532 \\
0.327\end{array}$ \\
\hline $\operatorname{Pgm} 2$ & $b$ & $0.68^{* *}$ & $-0.06^{* *}$ & $-0.13^{* *}$ & $-0.34^{* *}$ & $-0.18^{* *}$ & 0.598 \\
\hline $6 \mathrm{Pgd} 1$ & $\begin{array}{l}a \\
b \\
c \\
d \\
e\end{array}$ & $\begin{array}{l}0.09^{* *} \\
0.40^{* *} \\
0.10^{* *} \\
0.35^{* *} \\
0.35^{* *}\end{array}$ & $\begin{array}{l}-0.09^{* *} \\
-0.11^{* *} \\
-0.00 \\
-0.03^{*} \\
0.17^{* *}\end{array}$ & $\begin{array}{c}0.09^{* *} \\
0.07^{* *} \\
0.00 \\
-0.14^{* *} \\
-0.12^{* *}\end{array}$ & $\begin{array}{c}-0.09^{* *} \\
-0.25^{* *} \\
-0.03 \\
0.14^{* *} \\
-0.33^{* *}\end{array}$ & $\begin{array}{l}-0.03 \\
-0.14^{* *} \\
-0.10^{* *} \\
-0.34^{* *} \\
-0.10^{*}\end{array}$ & $\begin{array}{l}0.234 \\
0.207 \\
0.344 \\
0.172 \\
0.043\end{array}$ \\
\hline $6 P g d 2$ & $\begin{array}{l}a \\
b \\
c \\
e \\
f\end{array}$ & $\begin{array}{l}0.40^{* *} \\
0.11^{* *} \\
0.32^{* *} \\
0.31^{* *} \\
0.69^{*}\end{array}$ & $\begin{array}{c}-0.06^{* *} \\
-0.00 \\
-0.00 \\
-0.04^{*} \\
0.07^{*}\end{array}$ & $\begin{array}{c}-0.08^{*} \\
0.03^{*} \\
-0.02 \\
0.06^{* *} \\
-0.65^{* *}\end{array}$ & $\begin{array}{l}-0.06^{* *} \\
-0.12^{*} \\
-0.06^{* *} \\
-0.05^{* *} \\
-0.32^{* *}\end{array}$ & $\begin{array}{l}-0.22^{* *} \\
-0.04^{*} \\
-0.26^{* *} \\
-0.31^{* *} \\
0.10^{* *}\end{array}$ & $\begin{array}{l}0.222 \\
0.045 \\
0.321 \\
0.248 \\
0.160\end{array}$ \\
\hline $6 P g d 3$ & $\begin{array}{l}c \\
d \\
f \\
g\end{array}$ & $\begin{array}{l}0.17^{* *} \\
0.20^{* *} \\
0.09^{* *} \\
0.24^{* *}\end{array}$ & $\begin{array}{l}0.04^{* *} \\
-0.02 \\
-0.01 \\
-0.07^{* *}\end{array}$ & $\begin{array}{l}-0.23^{* *} \\
-0.37^{* *} \\
-0.03 \\
-0.26^{* *}\end{array}$ & $\begin{array}{c}0.01 \\
0.20^{* *} \\
-0.10^{* *} \\
0.07^{* *}\end{array}$ & $\begin{array}{c}-0.00 \\
-0.03^{*} \\
0.03^{*} \\
-0.02\end{array}$ & $\begin{array}{l}0.263 \\
0.243 \\
0.169 \\
0.056\end{array}$ \\
\hline $6 P g d 4$ & $\begin{array}{l}a \\
c \\
d \\
e \\
f\end{array}$ & $\begin{array}{l}0.19^{* *} \\
0.11^{* *} \\
0.16^{* *} \\
0.47^{* *} \\
0.51^{* *}\end{array}$ & $\begin{array}{l}-0.02 \\
-0.11^{* *} \\
-0.07^{* *} \\
-0.02 \\
0.18^{* *}\end{array}$ & $\begin{array}{c}-0.16^{* *} \\
0.04^{* *} \\
-0.06^{* *} \\
-0.02 \\
0.03^{*}\end{array}$ & $\begin{array}{l}-0.09^{* *} \\
-0.07^{* *} \\
-0.02^{* *} \\
-0.07^{* *} \\
-0.21^{* *}\end{array}$ & $\begin{array}{c}0.06^{* *} \\
0.01 \\
-0.03 \\
-0.39^{* *} \\
-0.54^{* *}\end{array}$ & $\begin{array}{l}0.100 \\
0.116 \\
0.360 \\
0.212 \\
0.040\end{array}$ \\
\hline $\begin{array}{l}\text { Averag } \\
\text { Mean o }\end{array}$ & distance & $\begin{array}{l}0.29 \\
4.28\end{array}$ & $\begin{array}{r}-0.02 \\
15.15\end{array}$ & $\begin{array}{r}-0.07 \\
38.90\end{array}$ & $\begin{array}{r}-0.08 \\
53.45\end{array}$ & $\begin{array}{r}-0.15 \\
65.84\end{array}$ & \\
\hline
\end{tabular}




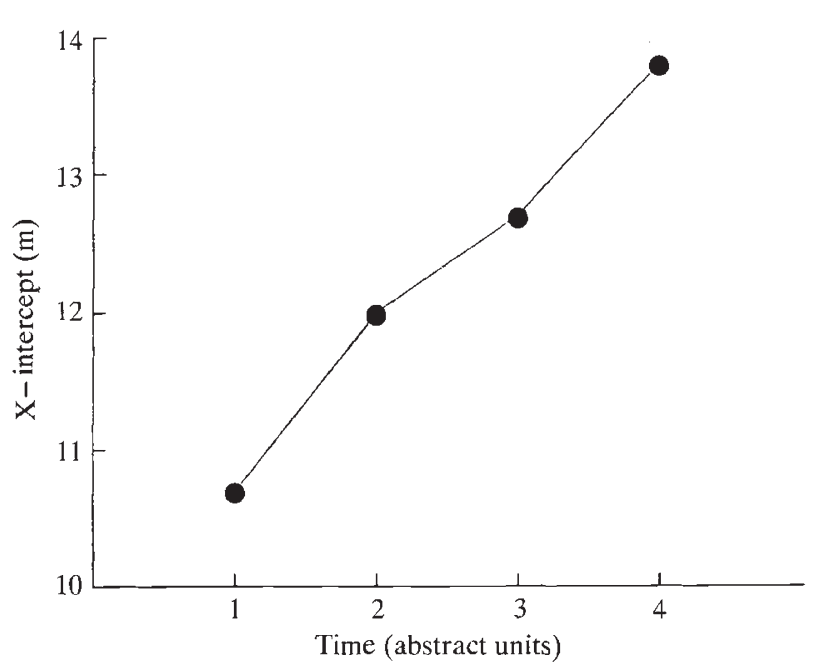

Fig. 4 Plot of the values of the $x$-axis intercept as a function of time estimated by linear interpolation from the cumulative correlograms from $t=1$ to $t=4$ (not shown).

and $e f$ at $(13,5)$. The representation at $t=4$ offers a single novelty: genotype $c g$ at $(16,3)$.

\section{Discussion}

Studies of natural and experimental plant populations have revealed that allele frequency distributions can be highly structured in space when there is microhabitat heterogeneity (Hamrick \& Holden, 1979; Turkington \& Harper, 1979). Theoretical approaches and practical evidence also agree in predicting positive autocorrelation between adjacent plants in predominantly selfing species (Allard, 1975), in those undergoing nearest-neighbour pollination (Turner et al., 1982) and where reproduction occurs vegetatively (Sokal \& Oden, 1978; Sokal \& Wartenberg, 1983; Oden, 1984; Shapcott, 1995). Short-distance spatial genetic structure exhibited by this stand of $A$. gramineum is unlikely to have evolved through the exploitation of a patchy environment. There are two compelling arguments that rule out this possibility. First, microhabitat heterogeneity was not detected, which is consistently supported by the considerable homogeneity obtained in the correlograms corresponding to different loci. Secondly, capsules have limited dispersal capacity and are seldom carried further than $0.5-1 \mathrm{~m}$ from the mother plant. In this respect, not even herbivore grazing is likely to be a factor determining larger dispersal distances, because the unpleasant smell given off by their leaves and the high content of colchicine in their vegetative parts dissuade or kill potential predators. Therefore, short-distance genetic structure in this stand is likely to have emerged as a natural consequence of the reproductive features of $A$. gramineum. The development of a nonrandom association of alleles within short distances might have been fostered by local genetic drift associated with capsule indehiscence and with a presumably greater physical separation between clumps at the time of foundation. It is feasible that a prolonged incidence of vegetative propagation enabled a continued wider coverage of the fertilized capsules.

Independent average correlograms for each of four age classes (Fig. 3b-e) reveal that, although there are slight discrepancies among the estimated sizes of homogeneous areas, overall profiles of genetic structure can be assumed to have been maintained, at least through the time span represented in our sample.

The large patch size estimated from the $x$-axis intercept in the mean multilocus correlogram (about $15 \mathrm{~m}$ ) is unlikely to be exclusively attributable to vegetative propagation. Examination of the genotypic site map of locus $6 P g d 4$ in Fig. 5 at $t=4$ (the nearest to the time of our sampling) supports this view by showing that clumps are often made up of mixed genotypes. Given that this observation indicates the action of outcrossing, the question arises as to how to interpret the high fixation index estimated in this stand $(F=0.249)$. The simplest explanation is that a great deal of selfing occurs, as the fixation index reflects the actual mating system within the population, and the high expected heterozygosity $\left(H_{\mathrm{e}}=0.349\right)$ could merely be an effect of vegetative reproduction. This possibility is weakly supported by our observations in the greenhouse that these plants exhibit a considerable degree of dichogamy. Alternatively, if population growth has been achieved mainly through vegetative reproduction, most outcrossing events may involve related or genetically identical plants. In this context, both expected heterozygosity and fixation indices could be high, even if outcrossing was the predominant strategy of sexual reproduction.

Can spatial autocorrelation throw some light on these alternatives? Thus far, the spatial genetic structure of this stand of $A$. gramineum has been considered through the global analysis of a large sample drawn at a single moment in time. The possibility of reliably ageing the plants and the large sample sizes obtained afford an excellent system for investigating the evolution of genetic structure patterns in this stand. Figures 3 and 5 suggest that the recruitment of new individuals has two interlinked effects. 

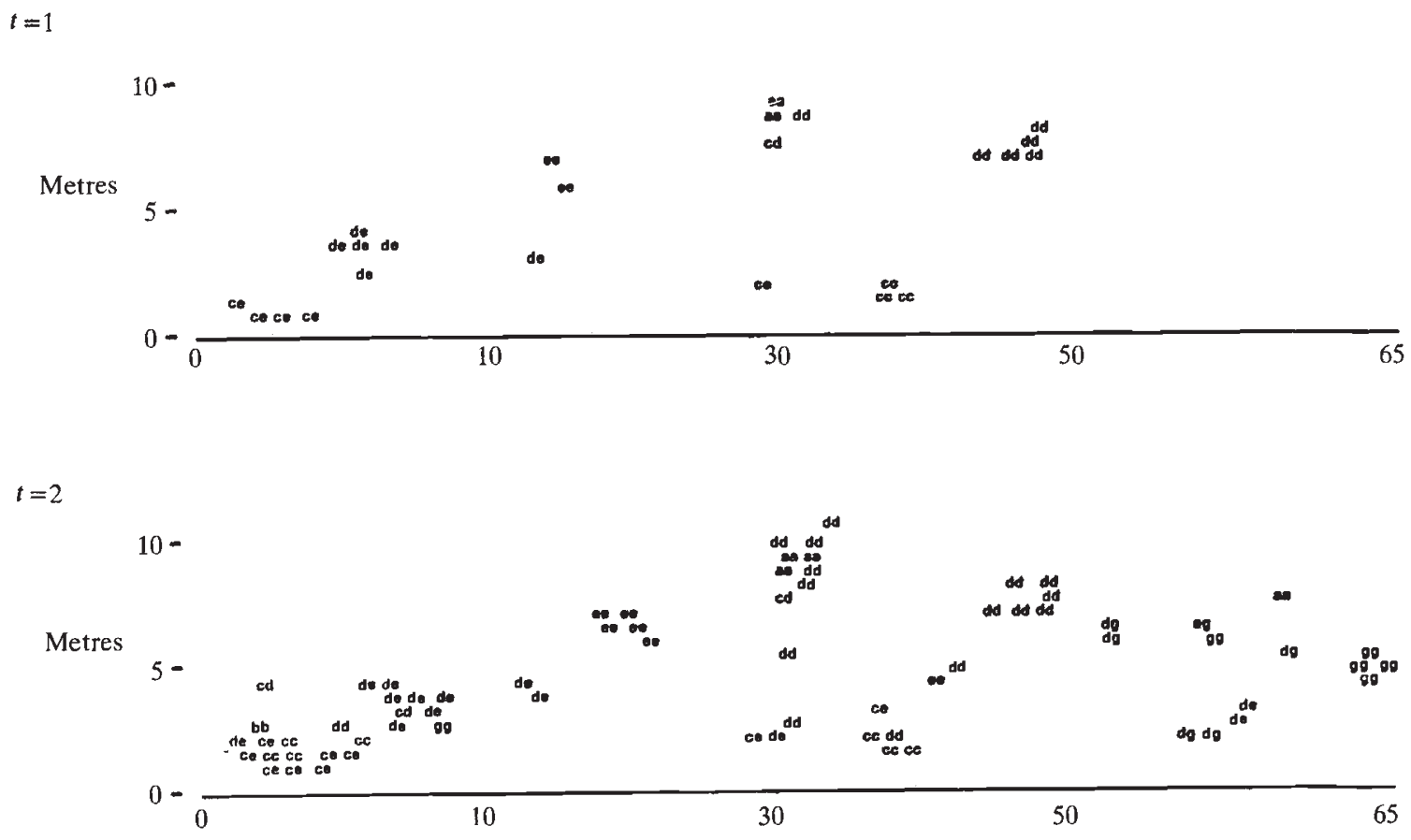

$t=3$

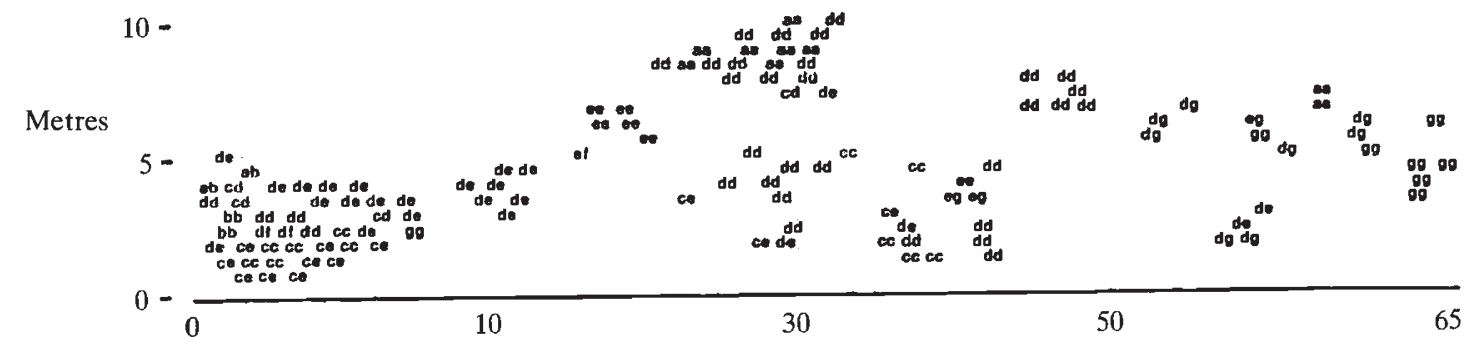

$t=4$

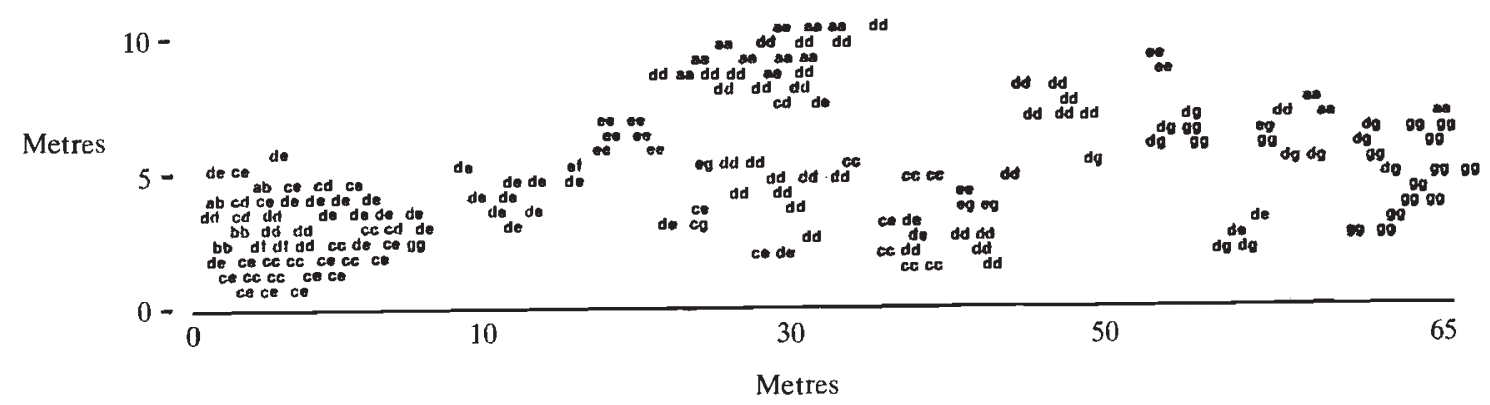

Fig. 5 Genotypic site map for Androcymbium gramineum of locus 6 Pgd4 through the four temporal subdivisions made; co-ordinates are approximate. 
First, it reduces the differences between nonadjacent localities, a phenomenon that we attribute to vegetative growth coupled with moderate levels of outcrossing and selfing. From the sequence of the genotypic site map of locus $6 P g d 4$ in Fig. 5, a key observation to reinforce this interpretation is that, while the number of genotypically identical heterozygous individuals in $\mathrm{CH}$ grows considerably from $t=1$ to $t=4$ (indicating vegetative growth), a large proportion of all the possible genotypic combinations do not occur in our sample (see Fig. 5 at $t=4$ ), possibly indicating limited outcrossing. There are two reasonable explanations for the appearance of new alleles. One of them is that they represent outcrossing events (either recent in time or attributable to the emergence of stocks of dormant seeds) involving intrapopulational localities not sampled. The other is that they derive from dead individuals that previously lived in the sampled area.

The second effect of population growth is the progressive enlargement of the size of homogeneous areas, as estimated from the average multilocus correlograms (Fig. 4). Qualitative evidence that this is not an artefact of decreasing sample size as one considers older age classes is furnished by the sequence represented in Fig. 5. It is worth emphasizing this result, because reports using computer simulations also describe progressive increases of the average $x$-intercept and the rapid generation of very large patches (Turner et al., 1982). In contrast to this stand, where the influence of vegetative reproduction on the spatial genetic structure seems to have been paramount, patch structure in Turner et al.'s (1982) simulations evolved solely because of nearestneighbour pollination and limited seed dispersal. Also, unlike the results obtained by Turner et al. (1982), heterozygotes in our sample were not predominantly found between patches of the two corresponding homozygotes.

These analyses suggest that this dense population of $A$. gramineum does not experience isolation by distance, because in that case we would expect an increase in the differences between adjacent localities over time. Furthermore, they indicate that prolific vegetative propagation overlaid with much lower levels of outcrossing and self-fertilization have strongly influenced the long-term development of its present short-distance genetic structure. This provides a consistent framework to explain the maintenance of high levels of variation in this species. Comparable data are scarce and unanimously suggest that, even in the long-term, the temporal component of differentiation is much less marked than the spatial component (Levin, 1976;
Linhart et al., 1979). Hopefully, these conclusions will soon be complemented by quantitative estimates of outcrossing rates in $A$. gramineum.

Our results agree with the general pattern that is emerging for plant populations, in which the development of substantial spatial structuring of molecular genetic variation is largely restricted to populations in which a significant portion of the offspring are produced by vegetative propagation or by selfing.

Finally, these results have significance for the conservation of variability in this endangered species. In a previous paper (Pedrola-Monfort \& Caujapé-Castells, 1996), we concluded that, as most of the allozymic and morphological variability of $A$. gramineum resided within populations, sampling intensively in the largest stand would minimize effort, while missing only very low-frequency alleles. Present evidence allows us to refine this conclusion by strongly suggesting that, if our interest is to obtain a consistent representation of the $\mathrm{A}$. gramineum gene pool, individuals should be separated by a minimum distance of $15 \mathrm{~m}$ in order to avoid the sampling of close relatives.

\section{Acknowledgements}

We are indebted to Amparo Ardanuy, who attended to the health and well-being of the Androcymbium specimens. Suggestions by Jordi Getman-Eraso helped to improve the formal aspects of this manuscript. This investigation is part of the projects DGICYT P13 93-1223 and CIRIT-CICYT QFN 95-4711.

\section{References}

ALlARD, R. w. 1975. The mating system and microevolution. Genetics, 79, 115-126.

ANTONOVICS, J. AND LEVIN, D. A. 1980. The ecological and genetic consequences of density-dependent regulation in plants. Ann. Rev. Ecol. Syst., 11, 411-452.

BarretT, s. C. H. AND KoHN, J. 1991. Genetic and evolutionary consequences of small population size in plants: implications for conservation. In: Falk, D. A. and Holsinger, K. E. (eds) Genetics and Conservation of Rare Plants, pp. 3-30. Oxford University Press, New York.

BRADShaw, A. D. 1972. Some of the evolutionary consequences of being a plant. Evol. Biol., 5, 25-47.

caujapé-CAstells, J. 1995. Aplicació dels conceptes d'ubiqüitat $i$ raresa allèlica a sis espècies del gènere Androcymbium (Colchicaceae). Ph.D. Dissertation, University of Barcelona.

ClifF, A. D. AND ORD, J. K. 1973. Spatial Autocorrelation. Pion, London.

(C) The Genetical Society of Great Britain, Heredity, 79, 341-349. 
CRUDEN, R. W. 1976. Intraspecific variation in pollenovule ratios and nectar secretion. Preliminary evidence of ecotypic adaptation. Ann. Mo. Bot. Gard., 63, 277-289.

DEWEY, S. E. AND HEYWOOD, J. S. 1988. Spatial genetic structure in a population of Psychotria nervosa. I. Distribution of genotypes. Evolution, 42, 834-838.

EPPERSON, B. K. AND CLEGG, M. T. 1986. Spatial-autocorrelation analysis of flower color polymorphisms within substructured populations of morning glory (Ipomoea purpurea). Am. Nat., 128, 840-858.

HAMRICK, J. L. AND HOLDEN, L. R. 1979. Influence of microhabitat heterogeneity on gene frequency distribution and gametic phase disequilibrium in Avena barbata. Evolution, 33, 521-533.

HUENNEKE, L. F. 1991. Ecological implications of genetic variation in plant populations. In: Falk, D. A. and Holsinger, K. E. (eds) Genetics and Conservation of Rare Plants, pp. 31-44. Oxford University Press, New York.

LEVIN, D. A. 1976. The organization of genetic variability in Phlox drummondii. Evolution, 31, 477-494.

LEVIN, D. A. AND KERSTER, H. W. 1974. Gene flow in seed plants. Evol. Biol., 7,139-220.

LINHART, Y. B., MITTON, J. B., STURGEON, K. B. AND DAVIS, M. L. 1979. Genetic variation in space and time in a population of ponderosa pine. Heredity, 46, 407-426.

ODEN, N. L. 1984. Assessing the significance of a spatial correlogram. Geogr. Annlr., 16, 1-16.

PEDROLA-MONFORT, J. AND CAUJAPÉ-CASTELLS, J. 1994. Allozymic and morphological relationships among Androcymbium gramineum, A. europaeum and $A$. psammophilum (Colchicaceae). Pl. Syst. Evol., 191, 111-126.

PEDROLA-MONFORT, J. AND CAUJAPÉ-CASTELLS, J. 1996. Allozyme diversity and morphological variation in the Andropcymbium gramineum complex (Colchicaceae). $P l$. Syst. Evol, 201, 149-162.

PERRY, D. J. AND KNOWLES, P. 1991. Spatial genetic structure within three sugar maple (Acer saccharum Marsh.) stands. Heredity, 66, 137-142.

SCHAAL, B. A. 1975. Population structure and local differentiation in Liatris cylindracea. Am. Nat., 109, 511-528.

SCHNABEL, A., LAUSHMAN, R. H. AND HAMRICK, J. L. 1991. Comparative genetic structure of two co-occurring tree species, Maclura pomifera (Moraceae) and Gleditsia triacanthos (Leguminosae). Heredity, 67, 357-364.
SCHOEN, D. J. AND LATTA, R. G. 1989. Spatial autocorrelation of genotypes in populations of Impatiens pallida and Impatiens capensis. Heredity, 63, 181-189.

SHAPCOTT, A. 1995. The spatial genetic structure in natural populations of the Australian temperate rainforest tree Atherosperma moschatum (Labill.) (Monimiaceae). Heredity, 74, 28-38.

SOKAL, R. R. 1979. Testing statistical significance of geographical variation patterns. Syst. Zool., 28, 227-232.

SOKAL, R. R. AND ODEN, N. L. 1978. Spatial autocorrelation in biology 1. Methodology. Biol. J. Linn. Soc., 10, 199-228.

SOKAL, R. R. AND WARTENBERG, D. E. 1983. A test of spatial autocorrelation analysis using an isolationby-distance model. Genetics, 105, 219-237.

SWOFFORD, D. L. AND SELANDER, R. B. 1989. BIOSYS-1, a Computer Program for the Analysis of Genetic Variation in Population Genetics and Biochemical Systematics, Version 1.7. Illinois Natural History Survey, Champaign, IL.

SYSTAT. 1992. sYSTAT version 5. Systat Inc., Evanston, IL.

TURKINGTON, R. AND HARPER, J. L. 1979. The growth, distribution and neighbour relationships of Trifolium repens in a permanent pasture. IV. Fine scale biotic differentiation. J. Ecol., 67, 245-254.

TURNER, M., STEPHENS, J. C. AND ANDERSON, W. W. 1982. Homozygosity and patch structure in plant populations as a result of nearest neighbor pollination. Proc. Natl. Acad. Sci. U.S.A., 79, 203-207.

WAGNER, D. B., SUN, Z.-X., GOVINDARAJU, D. R. AND DANCIK, B. P. 1991. Spatial patterns of chloroplast DNA and cone morphology variation within populations of a Pinus banksiana-Pinus contorta sympatric region. Am. Nat., 138, 156-170.

WARTENBERG, D. 1989. SAAP, version 4.3. Spatial Autocorrelation Analysis Program. Distributed by the author.

WRIGHT, s. 1938. Size of population and breeding structure in relation to evolution. Science, 87, 430-431.

WRIGHT, s. 1946. Isolation by distance under diverse systems of mating. Genetics, 31, 39-59.

Wright, s. 1978. Evolution and the Genetics of Populations, Vol. 4, Variability Within and Among Natural Populations, University of Chicago Press, Chicago. 